\title{
Impact of Biogas Blends with Diesel on Emission of Compression Ignition Engine
}

\section{A Arul Peter}

\begin{abstract}
Main objective of the work was to investigate the output like emission from compression ignition engine which has been run by diesel as well as the blends of biogas with diesel. Volume flow rate of biogas with petrol as a major parameter to reach the expected outcome. The engine was operated with diesel, and blends of biogas $15 \%, 25 \%$ and $35 \%$ with petrol. The study focused on the variation of outputs hydrocarbon, carbon monoxide(CO) Nitrous oxides(NOX) and smoke for the brake power generated by the engine. The engine exhibits better results when the proportion of biogas was increased.
\end{abstract}

Keywords : Biogas, Carbon monoxide, Compression Ignition engine. Emission, Hydro Carbon, Oxides of Nitrogen

\section{INTRODUCTION}

The depletion and fast consumption of fossil fuel enforces the mankind to search alternative energy resources to meet the demand. It should meet the emission standards and also renewable. Biogas from anaerobic digestion of animal substrate which is renewable compensates this demand.

\section{LITERATURE REVIEW}

Recent days rapid utilisation of fossil fuels on internal combustion engine turns the research towards alternative fuel. One of the best fuel was biogas blends with diesel which is used to run compression ignition engines. Comparatively less amount of hydrocarbon and nitrous oxides were emitted from the petrol engine operated with blends of biogas with gasoline through experiments by Propatham et al. (2008,2012). A detail study on compression ignition engine was made by Ray etal (2013) which is helpful and enlighten the researchers to do extraordinary work with the blends of biogas. Mustafi et al (2013) and Bank et al (2014a, b) conduct experiments and concluded that less amount of hydrocarbon and particulates were emitted from the engine. The same conclusion was exhibited from the experiments of Bora et al. (2013), Papagiannakis et al. (2007) and Shaoo et al (2011)

In this work the results were established for different brake powers of diesel engine using biogas blends with

Revised Manuscript Received on December 30, 2019.

* Correspondence Author

A Arul Peter*, Associate Professor, Department of Mechanical Engineering, Vels Institute of Science, Technology \& Advanced Studies (VISTAS), Chennai, Tamil Nadu, India.

(C) The Authors. Published by Blue Eyes Intelligence Engineering and Sciences Publication (BEIESP). This is an open access article under the CC BY-NC-ND license (http://creativecommons.org/licenses/by-nc-nd/4.0/) diesel. The outputs were compared with engine run by diesel alone.

\section{MATERIALS AND METHODS}

The processes anaerobic digestion was adapted to produce biogas from kitchen waste with water. Then it is allowed to pass through the water and compressed into the cylinder. The gas was injected to the diesel engine with diesel through regulator to maintain the blend ratio at the end of compression stroke.

\section{EXPERIMENTAL SETUP}

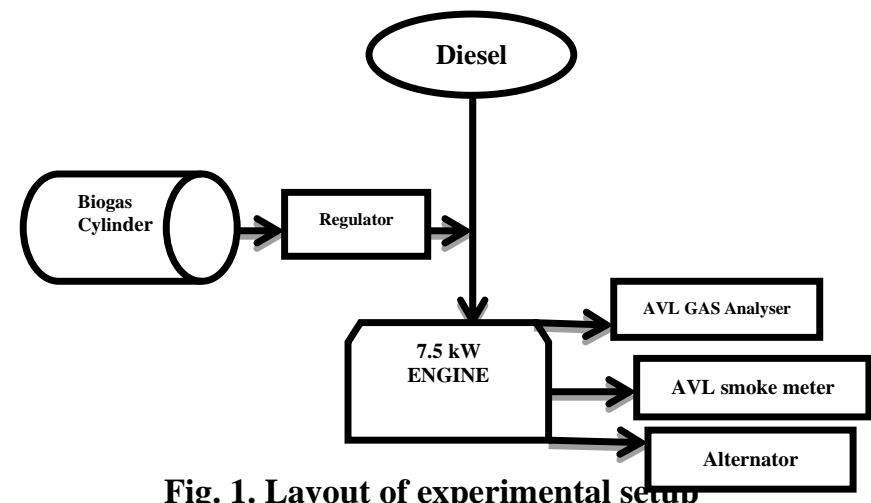

The layout of experimental setup was shown in fig 1 . Kirloskar water cooled engine of $7.5 \mathrm{~kW}$ direct injection which has get the fuel from diesel tank and biogas cylinder. The compression ratio is $18: 1$ and the injection pressure was 200 bar. The biogas was supplied to the engine with diesel at the end of compression stroke. AVL gas analyser, smoke meter and alternator was connected to the engine to get the output. The engine was operated with diesel Bio15, 25 and 35 blends to measure emission at different load conditions.

\section{RESULTS AND DISCUSSION}

\section{A. Effect on specific fuel consumption}

Fig 2 depicted the specific fuel consumption (sfc) of diesel and blends of biogas with diesel for various brake power. It was observed decrease in sfc due to the increment of load on the engine for all kinds of fuel. The inference from the observations it was low for diesel alone and proportionally increased with the blends of biogas with diesel. The reduction in energy content of fuel mix needs more amount of fuel of consumption to generate the same brake power. At low loads 2.5 time increase in sfc was observed in bio35 compared with diesel. At high load it was reduced and equal to 1.25 times of diesel sfc in case of bio35 blend from the experiments. 


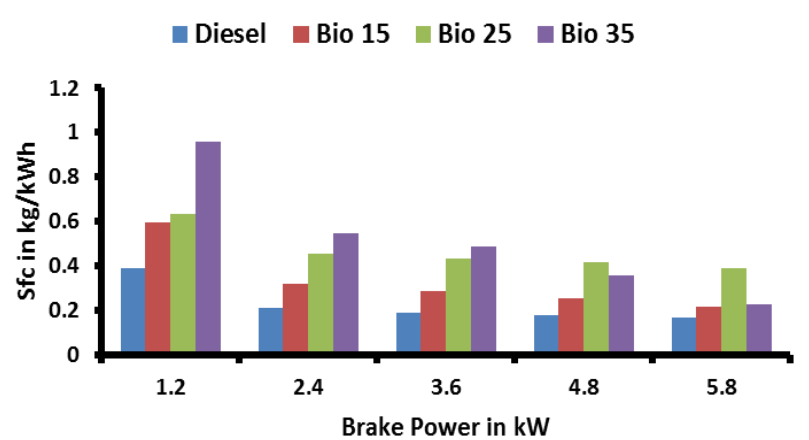

Fig. 2. Brake Power vs specific fuel consumption

\section{B. Effect on brake thermal efficiency}

It was observed from the plot shown in fig 3 the diesel exhibits more brake thermal efficiency at all load condition. The physical mechanism for this phenomenon was more output extraction with minimum consumption of diesel. Bio 15 blend is better than other two blends. Bio 25 and Bio 35 exhibited low thermal efficiency at higher brake power.

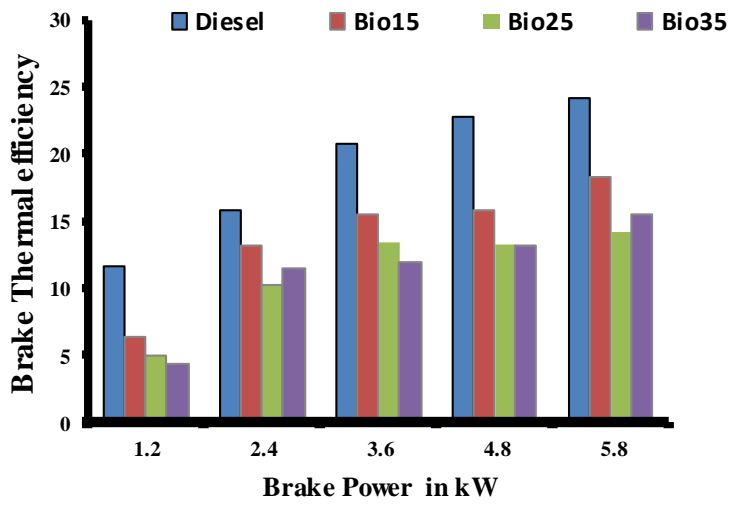

Fig.3. Brake Power vs brake thermal efficiency

\section{Effect on NOx emission}

Fig 4 exhibits diesel emitted higher NOx at all brake powers and it was continuously decreased at all load conditions. The root cause for reduction in dual fuel mode was flame quenching which reduces temperature inside the cylinder due to the increase in brake power. The low temperature restricted reaction of nitrogen with oxygen.

- Diesel $=$ Bio $15=$ Bio $25=$ Bio 35

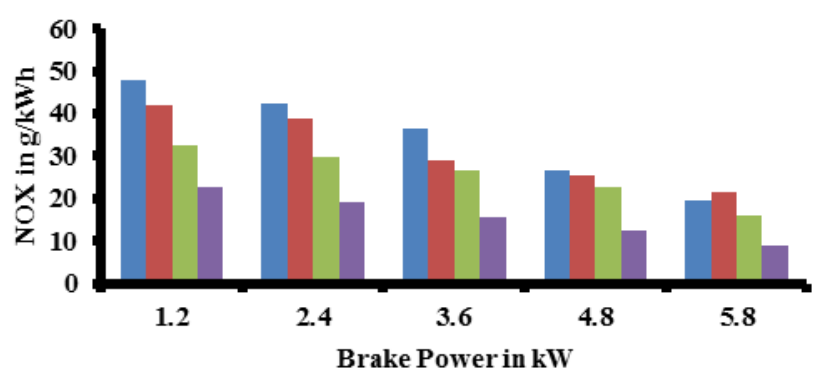

Fig. 4. Brake Power vs NO${ }_{x}$ emission

\section{Effect on HC emission}

The variation of hydrocarbon emission at different brake power was shown in fig.5. This emission was increases with increase in proportion of blends at 1,2 BP nearly 2.5 times of diesel for bio 35 blend. The same trend was observed upto 5,8 kW BP. At high brake power it was reduced drastically due to complete combustion for all types of fuel.

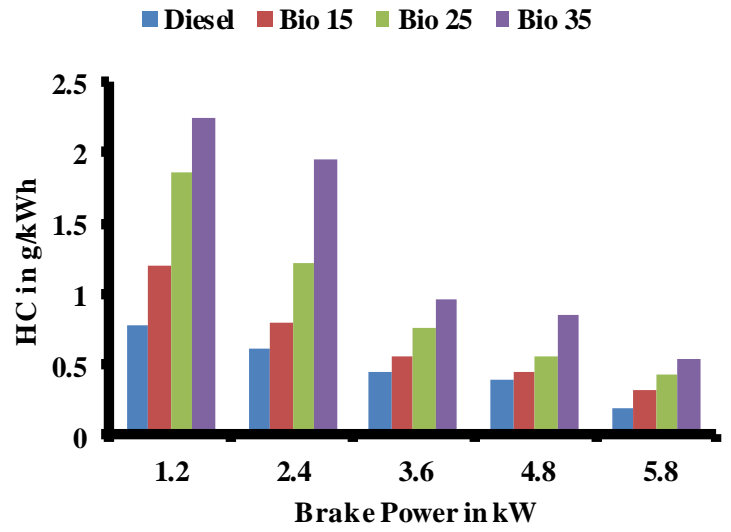

Fig.5. Brake Power vs HC emission

\section{E. Effect on CO emission}

The spectrum of $\mathrm{CO}$ variation at different BP was shown in fig 6. At low loads due to incomplete combustion the emission of $\mathrm{CO}$ is more for all fuels. It was observed the decreasing trend when the biogas is added to the diesel. At $5.8 \mathrm{~kW}$ the complete combustion reduced $\mathrm{CO}$ emission. It was appreciable in case of Bio35 blend with diesel.

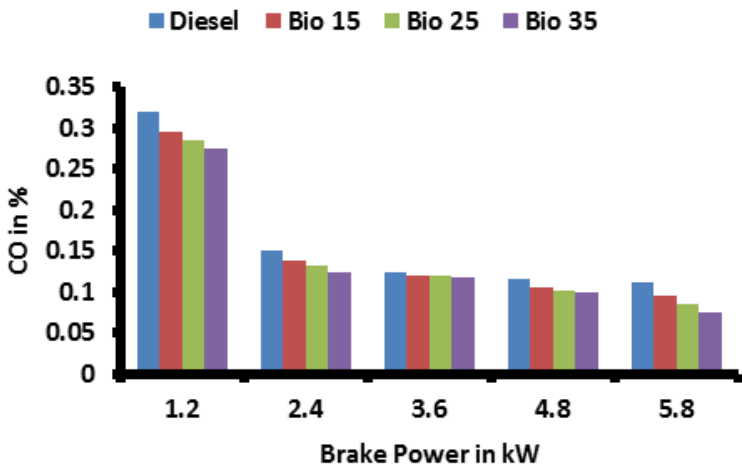

Fig.6. Brake Power vs CO emission

\section{F. Effect on smoke opacity}

Fig 7 depicted smoke opacity throughout the brake powers of engine. The heterogeneous mixture of air and diesel emitted more soot than homogeneous mixture of air and biogas blends with diesel. It was clearly indicated that reduction in soot formation occurred in homogeneous BIO 35 blend with diesel measured by AVL smoke meter. 


\section{Diesel $\square$ Bio $15 \square$ I}

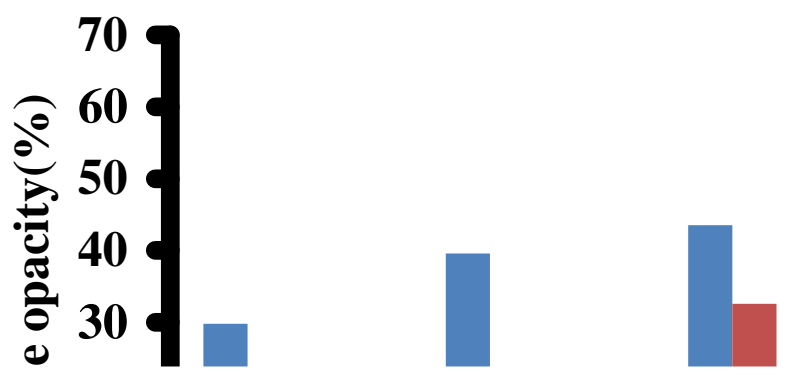

Fig.7. Brake Power vs smoke opacity

\section{CONCLUSION}

Experiments were conducted on the CI engine by utilising diesel and blends of biogas with diesel. It was observed that BIO 15 has optimum mix at all BP of the engine. At full load it consumes less sfc, $0.35 \mathrm{~g} / \mathrm{kWh} \mathrm{HC}$ emission and $0.09 \%$ of $\mathrm{CO}$ emission. This biogas mix with diesel will meet the energy demand and electricity generation in future.

\section{REFERENCES}

1. D.Barik, S.Murugan, "Investigation on combustion performance and emission characteristics of a DI (direct injection) diesel engine fueled with biogas-diesel in dual fuel mode," Energy vol 72, 2014a, pp. 760-771.

2. D Barik, S Murugan, "Simultaneous reduction of NOx and smoke in a dual fuel DI diesel engine," Energy Convers Manag, vol. 84, 2014b, pp. 217-226.

3. BJ. Bora, BK. Debnath, N. Gupta, UK. Saha, N. Sahoo, "Investigation on the flow behaviour of a venturi type gas mixer designed for dual fuel diesel engines," Int J Emerg Technol Adv Eng, vol.3, 2013, pp.202-209.

4. NN. Mustafi, RR.Raine, S.Verhelst, "Combustion and emissions characteristics of a dual fuel engine operated on alternative gaseous fuels. ,"Fuel, 2013, vol.109, 2013, pp. 669-678.

5. E. Porpatham, A. Ramesh, B. Nagalingam, "Investigation on the effect of concentration of methane in biogas when used as a fuel for a spark ignition engine. Fuel Issue.87, vol. 9, 2008, pp. 1651-1659.

6. E. Porpatham, A. Ramesh, B. Nagalingam, "Effect of compression ratio on the performance and combustion of a biogas fuelled spark ignition engine," Energy Convers Manag vol. 95, 2012, pp. 247-256.

7. N.H.S.Ray, M.K.Mohanty, R.C. Mohanty, "A Study on Application of Biogas as fuel in Compression Ignition Engines," International Journal of Innovations in Engineering and Technology," Issue 1, vol. 3, 2013. pp. 239-245.

8. BB. Sahoo, "Clean development mechanism potential of compression ignition diesel engines using gaseous fuel in dual fuel mode. Ph.D thesis, Centre for Energy, 2011, IIT Guwahati, India.

\section{AUTHORS PROFILE}

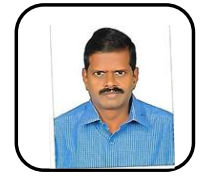

Dr. A. Arul Peter is an Associate Professor in Department of Mechanical Engineering, VISTAS, Chennai. He had done his research work on "Study of heat and mass transport through concrete exposed to elevated temperatures" in IIT Roorkee. His areas of interests are FEA, CFD, I.C Engines, heat and mass transfer and alternative energy resources. 